\title{
Hitchhikers in Honey: An investigation of the inhibitory mechanisms of bacteria found in honey
}

\author{
Emma Letcher ${ }^{\mathrm{a}}$ and Davida S. Smyth ${ }^{\mathrm{a}}$
}

\begin{abstract}
Honey has a stable physiochemical composition that contributes to its long shelf life and has been noted as an antimicrobial substance for centuries. Although it is common knowledge that honey affords some antimicrobial properties, the specific mechanisms behind this remain elusive. This paper hypothesizes that the microorganisms in certain raw honeys contribute towards their antimicrobial properties. In our study, we analyzed several raw and processed honey samples to determine their microbial constituents. The antimicrobial potential of the isolated microbes was tested using several clinically relevant bacteria including Escherichia coli, Staphylococcus aureus, Staphylococcus epidermidis and Pseudomonas aeruginosa. Of the tested honeys, Manuka (New Zealand) and Wildflower honey (Tennessee, USA) contained microorganisms exhibiting antimicrobial activity. All the isolated colonies grew on MacConkey and Mannitol agar and generated bands for the 16S rRNA gene implying that they were bacteria. This paper concludes that bacteria isolated from honey could be a new area of research within the topic of antimicrobial honey samples.
\end{abstract}

Keywords: honeybee; antimicrobial; microbes; beneficial; raw honey; gram positive bacteria

Certain strains of bacteria are developing new ways to resist antibiotics. This presents great challenges to healthcare providers and patients alike as it increases the length of stay in hospitals, requires more intensive care, and is more costly [1]. To combat these "super bugs", more research around traditional antibiotics is needed. Honey from Apis mellifera (A. mellifera), commonly known as the Western Honeybee has been utilized as a wound dressing and honey was regarded as a substance of immense importance in ancient times [2].

The specific mechanisms behind the antimicrobial properties of honey have not been fully realized, but most relevant literature suggests that multiple factors are at play. The physicochemical composition, including the high concentration of sugars, low moisture content, and the low $\mathrm{pH}$ level contribute to its long shelf life and are considered the universal antibacterial factors of all honeys [3]. In addition to these universal factors, different honeys have different natural additives that make them more antimicrobial than others. There are two known antimicrobial additives that bees add to honey. One is glucose oxidase, an enzyme that is produced in the honeybee salivary gland that catalyzes the oxidation of glucose to gluconic acid, and also creates hydrogen peroxide $\left(\mathrm{H}_{2} \mathrm{O}_{2}\right)$ in the process [4][5][6]. The other is bee defensin-1, a peptide secreted by the honeybee hypopharyngeal glands. This peptide is active against Gram-positive bacteria and plays a key role in the health of bee larvae [3]. Honey is also thought to have different antimicrobial properties depending on the type of flower that bees retrieve nectar from. This is particularly the case with monofloral Manuka honey, widely regarded as one of the most active antimicrobial honeys on the market [7].

The production of honey has many variables. There will always be slight variations between every bottle of honey from the same hive because of environmental impacts such as heat and humidity. Regardless of this variation, current literature strongly suggests that raw, unpasteurized honey, has broad spectrum antibacterial activity against pathogenic bacteria [8]. This paper focuses on the antibacterial characteristics of microorganisms that were isolated from various honey types and their capacity to inhibit the growth of several clinically relevant strains of bacteria.

\section{Methods and Materials}

\section{Collection}

A variety of raw and processed honey bottles were purchased over a period of three weeks from various regions of the United States. Filtered honey (H3) was purchased from a drug store and monofloral Manuka honey (H4), because of its prominence in the literature as an antimicrobial substance [7]. All honey samples were sealed until use and once opened they were closed securely and labeled with the date of opening. The honey samples are listed in Table 1 . The only honey that can soundly be considered monofloral, nectar that comes from one type of flower, is the Manuka honey which is nectar collected from the Leptospermum scoparium (L. scoparium) plant only. All other honeys in these experiments would be considered multifloral honey, nectar that comes from multiple types of flowers.

Table 1 - Honey samples origin and type

\begin{tabular}{cccc}
\hline Sample Name & Purchasing Location & Origin & Type of Honey \\
H1 & Sullivan County, New York & Sullivan County, New York & Wildflower Honey \\
H2 & Dutchess County, New York & Dutchess County, New York & Wildflower Honcy \\
H3 & Drug Store, NYC & Blend (Argentina, USA, Turkey) & Filtered Honey \\
H4 & Gourmet Food Store, NYC & New Zealand & Monofloral Manuka Honey \\
& Wilson County, Tennessee & Wilson County, Tennessee & Wildflower Honey \\
\hline
\end{tabular}

Test Microorganisms

The test bacteria (Escherichia coli NCTC 10538, Staphylococcus aureus ATCC 25923, Staphylococcus epidermidis ATCC 14990, and Pseudomonas aeruginosa ATCC 10145) were obtained from Microbiologics. Bacterial strains were incubated at $37^{\circ} \mathrm{C}$ for 24 hours on Tryptic Soy Agar (TSA) (Oxoid). 
Research Article

\subsection{Microorganism Analysis}

In order to determine if the honey contained microorganisms, the samples were diluted 1:1 with sterile deionized water and vortexed for 5 minutes each. $50 \mu$ of each solution was spread onto TSA plates. The plates were incubated at $30^{\circ} \mathrm{C}$ for 24 hours. Individual colonies were subsequently stored in a mixture of glycerol and TSB at $-80^{\circ} \mathrm{C}$.

\subsection{MacConkey and Mannitol Plate Assay}

Individual colonies were patched onto both MacConkey (Oxoid) and Mannitol Plates (Oxoid). The plates were incubated at $30^{\circ} \mathrm{C}$ for 24 hours.

\subsection{Patching Assay}

To assess the inhibitory effect of microbial isolates on tester strains of bacteria each tester strain was re-suspended to a $0.5 \mathrm{McF}$ arland Standard and spread onto TSA plates. Honey isolates were patched onto each tester strain and incubated at $37^{\circ} \mathrm{C}$ for 24 hours.

$2.4 \quad$ Sample Preparation, Polymerase Chain Reaction and Gel electrophoresis

A small amount of each honey isolate was mixed with sterile distilled water and boiled for 10 mins [8]. $2 \mu 1$ of this boiled lysate was used in each PCR reaction. A broad range 16S ribosomal RNA (rRNA) gene polymerase chain reaction (PCR), was used to identify the honey isolates. Forward primer BAC16S-F (TGGAGCATGTGGTTTAATTCGA) and reverse primer BAC16S-R (TGCGGGACTTAACCCAACA) were used to target the V4 region of the 16S SSU rRNA [10]. PCR products were run on a $1 \%$ agarose gel in $0.5 x$ TBE buffer [8]. Genomic DNA from strain Mu50 was used as a positive control and a DNA negative sample was used as a negative control.

\section{Results}

\subsection{Microorganisms in Honey Samples}

4 of the 5 honey samples produced microorganism growth, with $\mathrm{H} 2$ honey producing the most growth and $\mathrm{H} 1$ producing no growth (Table 2). Up to 24 colonies from the four samples that produced growth were patched onto additional TSA plates and incubated at $30^{\circ} \mathrm{C}$ for 24 hours, and stored in glycerol and TSB at $-80^{\circ} \mathrm{C}$ for future experiments.

Table 2 - Number of colonies seen after incubation

Honey Sample Number of Colonies (1:1 Dilution) Colony Notation

\begin{tabular}{ccc} 
H1 & 0 & N/A \\
$\mathrm{H} 2$ & 75 & $\mathrm{H} 2.1-\mathrm{H} 2.24$ \\
$\mathrm{H} 3$ & 2 & $\mathrm{H} 3.1-\mathrm{H} 3.2$ \\
$\mathrm{H} 4$ & 6 & $\mathrm{H} 4.1-\mathrm{H} 4.6$ \\
$\mathrm{H} 5$ & 14 & $\mathrm{H} 5.1-\mathrm{H} 5.14$ \\
\hline
\end{tabular}

All colonies were re-labeled to allow for distinction between colonies in future experiments (Table 2).

\subsection{Patching Assay Results}

Honey type H4 (Manuka) and H5 (Wildflower, TN) contained the most inhibitory colonies towards our tester strains S. aureus and S. epidermidis (Table 3). Colonies from the same honey sample behaved differently with the same tester strains indicating that these may be all different microorganisms.

Table 3 - Size of the inhibitory zone around the honey isolates

\begin{tabular}{lllll}
\hline Honey Sample & S. aureus & P. aeruginosa & E. coli & S. epidermidis \\
H4.1 & $.5 \mathrm{~mm}$ & $\mathrm{NZ}$ & $\mathrm{NZ}$ & $2 \mathrm{~mm}$ \\
$\mathrm{H} 4.2$ & $.5 \mathrm{~mm}$ & $\mathrm{NZ}$ & $\mathrm{NZ}$ & $2 \mathrm{~mm}$ \\
$\mathrm{H} 4.5$ & $2 \mathrm{~mm}$ & $\mathrm{NZ}$ & $\mathrm{NZ}$ & $1 \mathrm{~mm}$ \\
$\mathrm{H} 4.6$ & $2 \mathrm{~mm}$ & $\mathrm{NZ}$ & $\mathrm{NZ}$ & $2 \mathrm{~mm}$ \\
$\mathrm{H} 5.1$ & $\mathrm{NZ}$ & $\mathrm{NZ}$ & $\mathrm{NZ}$ & $1 \mathrm{~mm}$ \\
$\mathrm{H} 5.2$ & $\mathrm{NZ}$ & $\mathrm{NZ}$ & $\mathrm{NZ}$ & $1 \mathrm{~mm}$ \\
$\mathrm{H} 5.3$ & $.25 \mathrm{~mm}$ & $\mathrm{NZ}$ & $\mathrm{NZ}$ & $.5 \mathrm{~mm}$ \\
\hline
\end{tabular}

$\mathrm{NZ}=$ no zone

3.3 MacConkey and Mannitol Plate Assay Results

All honey isolates were patched onto both Mannitol and MacConkey plates. All organisms grew on the plates but none exhibited fermentation. The phenotype of the isolates varied widely even within colonies from the same honey sample, indicating that each colony may be a different bacteria (Table 4 and Table 5). Although the selective media did not indicate whether these microorganisms were fermenters or not, this assay further concludes that the colony growth from the same honey sample is likely different types of bacteria because of the way they reacted differently to the Mannitol and MacConkey plates.

Table 4- MacConkey Plate Results

\begin{tabular}{lll}
\hline Honey Sample & Agar Color & Bacteria Color \\
H4.1 & Yellow & Yellow \\
H4.2 & Yellow & Yellow \\
H4.5 & Yellow & Yellow \\
H4.6 & Yellow & Yellow \\
H5.1 & Yellow & Yellow \\
H5.2 & Yellow & Yellow \\
H5.3 & Yellow & Yellow \\
\hline
\end{tabular}

Table 5- Mannitol Plate Results

\begin{tabular}{lll}
\hline Honey Sample & Agar Color & Bacteria Color \\
H4.1 & Pink & Pink \\
H4.2 & Pink & Pink \\
H4.5 & Pink & Yellow \\
H4.6 & Pink & Yellow \\
H5.1 & Pink & Pink \\
H5.2 & Pink & Yellow \\
H5.3 & Pink & Pink \\
\hline 3.4 & Polymerase Chain Reaction and Gel Electrophoresis
\end{tabular}

\section{Results}

8 samples were selected based on their antimicrobial activity to undergo a PCR and Gel Electrophoresis with $16 \mathrm{~S}$ rRNA primers to identify the species of the microorganism. All the samples produced a 16S rRNA amplicon (Image 1) implying that they were bacteria. Positive and negative controls exhibited the expected banding pattern. 


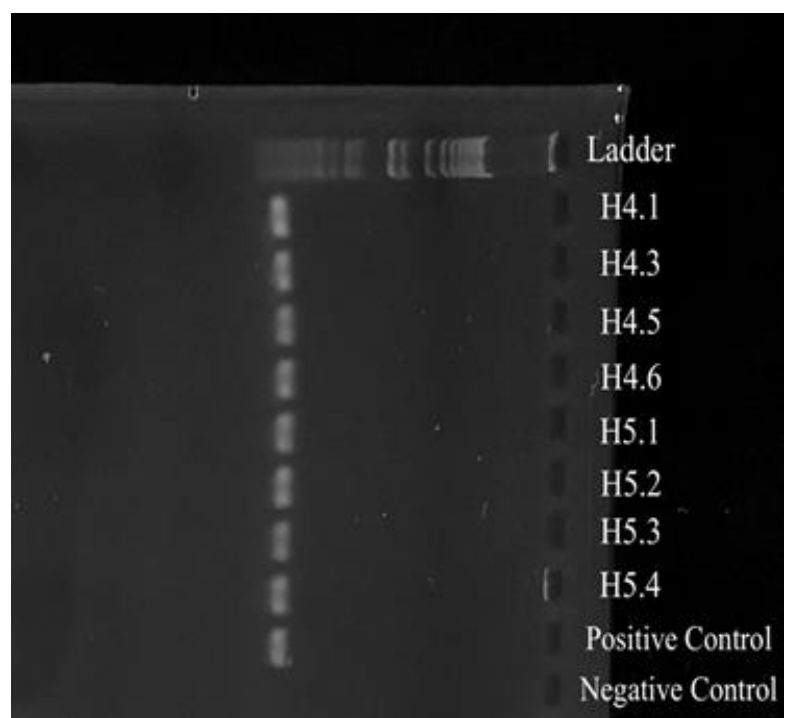

Fig 1- Gel Electrophoresis

\section{Discussion}

In this study we sought to determine if honey harbored microorganisms and to see if these microorganisms could produce antibacterial factors. We determined that isolated microorganisms in honey were bacteria, and that certain isolates developed larger zones of inhibition than others when they were patched onto Gram positive strains S. epidermidis and $S$. aureus. The honeys with the greatest zones of inhibition were Manuka Honey from New Zealand and Wildflower honey from Tennessee. Future experiments will utilize sequencing technology to identify the specific types of bacteria and understand the inhibitory mechanisms at play. There have been a few other studies done on this topic, however, those studies focus on international honey samples from Poland and countries in Africa [12][13]. This studies scope was primarily focused on honey produced and packaged in the United States except for the Manuka honey (New Zealand) and the filtered honey (Argentina, USA, and Turkey). Similar antimicrobial activity was seen in both the Manuka and Wildflower honey from Tennessee, and therefore opens more questions as to what inhibitory role the bacteria are playing towards the bacterial tester strains.

Other significant findings in this study were the fact that bacteria isolates that grew from the same honey sample were different in the way they resisted the above mentioned strains and the way they appeared phenotypically on Mannitol and MacConkey plates. This diversity is an area that could be explored further in dissecting where these bacteria originate, whether in the bee, the hive, or from human intervention. A more controlled experiment focusing on different environmental factors such as temperature and humidity of a specific hive would also reveal more conclusive findings about what types of bacteria survive in different hive environments.

These experiments emphasize that honey is a rich substance full of antimicrobial potentials that have yet to be discovered. Although the mechanisms that afford honey with this unique capacity continue to be researched, the antimicrobial properties of bacteria itself is an area that must have attention devoted to it.

\section{Acknowledgements}

This Summer Undergraduate Research Experience would not have been possible without the guidance and support of Davida Smyth, PhD and the other student members of the Smyth Lab. Dr. Smyth is a participant in the Tiny Earth Program of the University of Wisconsin and is grateful for their guidance and support. Ms Letcher was supported by a Eugene Lang Opportunity award and a Mohn Family Science and Social Justice Fellowship.

\section{References}

[1]Ventola C. L. (2015). The antibiotic resistance crisis: part 1: causes and threats. $\mathrm{P} \& \mathrm{~T}$ : a peer-reviewed journal for formulary management, 40(4), 277-283.

[2] Majno, G. (1975) Man and Wound in the Ancient World. Harvard University Press, Cambridge, MA, USA.

[3] Szweda, P. (2017) Antimicrobial Activity of Honey, Honey Analysis. Vagner de Alencar Arnaut de Toledo, IntechOpen, Chapter 10. doi: $10.5772 / 67117$

[4] Oshashi, K. (1999) Expression of amylase and glucose oxidase in the hypopharyngeal gland with an agedependent role change of the worker honeybee (Apis mellifera L.). European Journal of Biochemistry 265, 127-133.

[5] Strelec, I. (2018) Glucose oxidase activity and hydrogen peroxide accumulation in Croatian honeys. Croation Journal of Food Science and Technology. DOI: 10.17508/CJFST.2018.10.1.06

[6] Bucekova, M. (2014) Honeybee glucose oxidase-its expression in honeybee workers and comparative analyses of its content and $\mathrm{H}_{2} \mathrm{O}_{2}$-mediated antibacterial activity in natural honeys. Naturwissenschaften. 101:661-670. doi; 10.1007/s00114-014-1205-z

[7] Bucekova, M. (2019) Antibacterial Activity of Different Blossom Honeys: New Findings Molecules, 24, 1573; doi:10.3390/molecules24081573.

[8] Mandal, M. D., \& Mandal, S. (2011). Honey: its edicinal property and antibacterial activity. Asian Pacific journal of tropical biomedicine, 1(2), 154-160; doi:10.1016/S2221-1691(11)60016-6

[9] McClure-Warnier, J. A., Conly, J. M., \& Zhang, K. (2013). Multiplex PCR assay for typing of staphylococcal cassette chromosome mec types I to $\mathrm{V}$ in methicillin-resistant Staphylococcus aureus. Journal of visualized experiments : JoVE, (79), 50779; doi:10.3791/50779

[10] Kalyan D. Chavda, Michael J. Satlin, Liang Chen, Claudia Manca, Stephen G. Jenkins, Thomas J.Walsh, Barry N. Kreiswirth (2016). Evaluation of a Multiplex PCR Assay To Rapidly Detect Enterobacteriaceae with a Broad Range of $\beta$ Lactamases Directly from Perianal Swabs Antimicrobial Agents and Chemotherapy. 60 (11) 6957-6961; doi: 10.1128/AAC.01458-16

[11] Sinsimer D, Leekha S, Park S, Marras SA, Koreen L, 
Research Article

Willey B, Naidich S, Musser KA, Kreiswirth BN (2005). Use of a multiplex molecular beacon platform for rapid detection of methicillin and vancomycin resistance in Staphylococcus aureus. $\mathbf{J}$ Clin Microbiol 43:4585-4591. doi:10.1128/JCM.43.9.4585-4591.2005.

[12] Pajor, M. (2018). The Antimicrobial Potential of Bacteria Isolated from Honey Samples Produced in the Apiaries Located in Pomeranian Voivodeship in
Northern Poland. International Journal of Environmental Research and Public Health. 15, 2002; doi:10.3390/ijerph15092002.

[13] Olaitan, P. B., Adeleke, O. E., \& Ola, I. O. (2007). Honey: a reservoir for microorganisms and an inhibitory agent for microbes. African health sciences, 7(3), 159-165. doi:10.5555/afhs.2007.7.3.159. 